\title{
Synthesis, Growth, and Characterization of a New Thiourea and Bismuth Chloride Complex with Excellent Nonlinear Optical Properties
}

\author{
Liang Zhang ${ }^{1,2} \cdot$ Lina Zhou ${ }^{1,2} \cdot$ Baohong Hou ${ }^{1,2} \cdot$ Qiuxiang Yin ${ }^{1,2,3} \cdot$ Chuang Xie ${ }^{1,2,3}$
}

Received: 26 February 2018 / Revised: 11 March 2018 / Accepted: 14 March 2018 / Published online: 23 April 2018

(c) The Author(s) 2018

\begin{abstract}
Crystals of a new organometallic nonlinear optical (NLO) compound, di- $\mu$-chloro-bis[chlorotri(thiourea)bismuth(III)]pentachloro(thiourea)bismuth-ate(III) (DCBPB), have been successfully grown from formic acid aqueous solutions of thiourea and bismuth chloride by a slow evaporation technique. The crystal structure and atomic composition of DCBPB have been confirmed by single crystal X-ray diffraction (SCXRD), Fourier transform infrared spectra, and elemental analysis. The SCXRD results proved that DCBPB crystallizes in triclinic space group P1 with unit cell dimensions of $a=7.0606(2) \AA$, $b=8.8106(4) \AA, c=16.3247(8) \AA, \alpha=99.242(4)^{\circ}, \beta=95.309(3)^{\circ}, \gamma=105.856(3)^{\circ}$, and $Z=2$. DCBPB crystal exhibits excellent transmittance from 500 to $2500 \mathrm{~nm}$ and green fluorescence with maximum emission at $508 \mathrm{~nm}$. The thermogravimetricdifferential scanning calorimetry (TG-DSC) analysis indicates that a solid-phase reaction took place at $170.1{ }^{\circ} \mathrm{C}$, whereas the decomposition temperature of the crystal material was $189^{\circ} \mathrm{C}$. The NLO property obtained by the Kurtz powder test showed that the second harmonic generation efficiency of DCBPB crystal is two-seventh of KDP crystal.
\end{abstract}

Keywords NLO $\cdot$ Organometallic $\cdot$ Thiourea $\cdot$ Bismuth chloride $\cdot$ TG-DTA

\section{Introduction}

After Franken et al. [1] first discovered the nonlinear optical (NLO) phenomenon in 1961, NLO crystal has attracted growing attention due to its outstanding applications in optical communications, optical storage devices, optical limiting, laser frequency conversion, and optical switching devices [2-4].

Compared to inorganic NLO materials, organic NLO compounds, which show a great nonlinear coefficient, are easy to design and synthesize; however, they exhibit mechanical properties and stability not as good as inorganic

Chuang Xie

acxie@tju.edu.cn

1 School of Chemical Engineering and Technology, Tianjin University, Tianjin 300072, China

2 National Engineering Research Center of Industrial Crystallization Technology, Tianjin University, Tianjin 300072, China

3 National Collaborative Innovation Center of Chemical Science and Engineering (Tianjin), Tianjin 300072, China
NLO materials. Semi-organic systems were, therefore, introduced to balance the NLO properties and mechanical performance. In particular, organometallic complexes were demonstrated to be promising NLO materials with favorable hardness, bandgap, melting point, and growth habit [5-7] due to coordination and chemical bonding [8-10].

Among coordination compounds, thiourea possesses a strong coordinating capability with metals because of its lone pair electrons of nitrogen and sulfur atoms [11, 12]. Besides, coordinating thiourea with metal halide can provide acentric symmetrical structure, which is required to produce a high-optical transparent NLO crystal with a large nonlinear coefficient [13]. In the past 20 years, several thiourea-based semi-organic NLO compounds have been discovered, such as bis-thiourea cadmium chloride (BTCC) [14], zinc thiourea chloride (ZTC) [15], zinc thiourea sulfate (ZTS) [16], $\alpha$-bismuth thiourea chloride ( $\alpha$-BTC) [17], $\beta$-bismuth thiourea chloride ( $\beta$-BTC) [18], and bismuth thiourea chloride dihydrate (TBNTNC) [19].

In this paper, we report the synthesis, growth, and characterization of di- $\mu$-chloro-bis[chlorotri(thiourea) bismuth(III)]-pentachloro(thiourea)-bismuth-ate(III) (DCBPB), a new NLO crystal composed of thiourea and 




Scheme 1 Synthetic route for DCBPB

bismuth chloride. The single crystals were harvested by a slow evaporation technique. The optical properties were characterized, and the thermostability was investigated, as well.

\section{Experimental Section}

DCBPB compound was synthesized according to Scheme 1 in a stoichiometric ratio of 3:7. Bismuth chloride (3.784 g, $12 \mathrm{mmol}, \geq 98 \mathrm{wt} \%$ ) was dissolved in 20 -mL formic acid aqueous solutions $(3: 2, V / V)$ in a 50 - $\mathrm{mL}$ jacketed crystallizer. A solution of thiourea $(2.131 \mathrm{~g}, 28 \mathrm{mmol}, \geq 99.0 \mathrm{wt} \%)$ and $20-\mathrm{mL}$ formic acid aqueous solutions $(3: 2, V / V)$ was added into the bismuth chloride solution at a rate of $21 \mathrm{~mL} / \mathrm{h}$ below $40{ }^{\circ} \mathrm{C}$ with a stirring rate of $200 \mathrm{r} / \mathrm{min}$. As the reaction started, the color of the solution turned into yellow from colorless, and a yellowish solid precipitated. The reaction was maintained for $10 \mathrm{~h}$ at a constant temperature of $40^{\circ} \mathrm{C}$. The precipitate was recrystallized three times using waterformic acid mixture $(2: 3, V / V)$; then, the saturated liquid of DCBPB in formic acid aqueous solutions $(3: 2, V / V)$ at $25^{\circ} \mathrm{C}$ was slowly filtered in a rinsed beaker using the filter paper and kept for slow evaporation at room temperature. Yellow single crystals were harvested in 10 days.

Crystals with the size of $0.16 \mathrm{~mm} \times 0.14 \mathrm{~mm} \times 0.10 \mathrm{~mm}$ were subjected to an single crystal X-ray diffraction (SCXRD) study at room temperature using a Rigaku-Rapid II diffractometer (Agilent, USA) with Mercury2 CCD area detector and graphite-monochromatized Mo K $\alpha$ radiation $(\lambda=0.71073 \AA)$. The structure of DCBPB was solved with the SHELXS and SHELXL packages. Powder X-ray diffractions were performed on a Rigaku D/max 2500 (Rigaku, Japan) using $\mathrm{Cu} \mathrm{K} \alpha$ radiation ( $1.5405 \AA$ ) over the $2 \theta$ range from $2^{\circ}$ to $50^{\circ}$ at a scanning rate of $8 \%$ min. Fourier transform infrared (FTIR) spectra of the DCBPB crystal were measured using a Nicolet 6700 FTIR spectrometer (Bruker, Germany) in the range of $400-4000 \mathrm{~cm}^{-1}$. Thermogravimetric (TG) analysis was carried out via TGA/DSC 1/500 (Mettler Toledo, Co., Switzerland) in the temperature range of $25-800{ }^{\circ} \mathrm{C}$ under the protection of nitrogen. Hot Stage Microscope (HSM, Olympus UMAD3) was used to observe the solid-state phase transition behavior from 25 to $170{ }^{\circ} \mathrm{C}$ at a heating rate of $5{ }^{\circ} \mathrm{C} / \mathrm{min}$. Differential scanning calorimetry (DSC) was performed by DSC 1/500 (Mettler Toledo, Co., Switzerland) under the protection of nitrogen. The diffuse reflection spectra in the range of 400-2500 nm were measured with a Lambda 750 UV-visible-near IR spectrophotometer (Perkin Elmer, USA). The fluorescence excitation and emission spectra were recorded with excitation at $368 \mathrm{~nm}$ using a Fluorolog-3 spectrophotometer (HORIBA Jobin-Yvon, USA). The second harmonic generation (SHG) test was performed via the Kurtz-Perry powder method [20], which uses the Q-switched Nd:YAG laser $(1064 \mathrm{~nm}, 10 \mathrm{~Hz}$, $6 \mathrm{~ns}$ ) to deliver the input energy of $5.4 \mathrm{~mJ} /$ pulse. The crystals of DCBPB and KDP were milled and sieved into a homogeneous particle size of $95-150 \mu \mathrm{m}$ for the SHG test.

\section{Results and Discussion}

\section{Crystal Structure}

The detailed crystallographic parameters of a DCBPB crystal are listed in Table 1. DCBPB belongs to a triclinic system, with the $\mathrm{P} 1$ space group, which is different from the reported bismuth thiourea chlorides $\alpha$-BTC (monoclinic, Cc) [17] and $\beta$-BTC (hexagonal, P3) [18]. The unit cell of DCBPB crystal (Fig. 1) contains three crystallographically different $\mathrm{Bi}^{3+}$ ions, which are in two coordination modes. In mode I, one $\mathrm{Bi}^{3+}$ ion coordinates five $\mathrm{Cl}^{-}$and one thiourea molecule $(1+5)$, which forms a mononuclear $\left[\mathrm{BiCl}_{5} \mathrm{SC}\left(\mathrm{NH}_{2}\right)\right]^{2-}$ anionic group. In mode II, the other two $\mathrm{Bi}^{3+}$ ions share three $\mathrm{Cl}^{-}$and each of them coordinates three thiourea molecules $(3+3)$, which forms a dinuclear $\left[\mathrm{Bi}_{2} \mathrm{Cl}_{4}\left(\mathrm{SC}\left(\mathrm{NH}_{2}\right)_{2}\right)_{6}\right]^{2+}$ cationic group. The two ionic groups are of the octahedral structure with $\mathrm{a} \mathrm{Bi}^{3+}$ ion at the center, $\mathrm{Cl}^{-}$, and thiourea molecule at the vertex. The positive ions consist of two octahedrons, which share the same chlorine-bridge bond $(\mathrm{Cl}(2)-\mathrm{Cl}(2))$.

Table 1 Crystallographic data of DCBPB

\begin{tabular}{ll}
\hline & $\mathrm{DCBPB}$ \\
\hline Formula & $\mathrm{C}_{3.5} \mathrm{H}_{14} \mathrm{Bi}_{1.5} \mathrm{Cl}_{4.5} \mathrm{~N}_{7} \mathrm{~S}_{3.5}$ \\
$M$ & 739.42 \\
Crystal system & Triclinic \\
Space group & $\mathrm{P} 1$ \\
Temperature $(\mathrm{K})$ & $293(2)$ \\
$a(\AA)$ & $7.0606(2)$ \\
$b(\AA)$ & $8.8106(4)$ \\
$c(\AA)$ & $16.3247(8)$ \\
$\alpha\left(^{\circ}\right)$ & $99.242(4)$ \\
$\beta\left({ }^{\circ}\right)$ & $95.309(3)$ \\
$\gamma\left({ }^{\circ}\right)$ & $105.856(3)$ \\
Cell vol. $\left(\AA^{3}\right)$ & $954.21(7)$ \\
$Z$ & 1 \\
$R_{1}$ & 0.0353 \\
${ }^{\circ} R_{2}$ & 0.1019
\end{tabular}




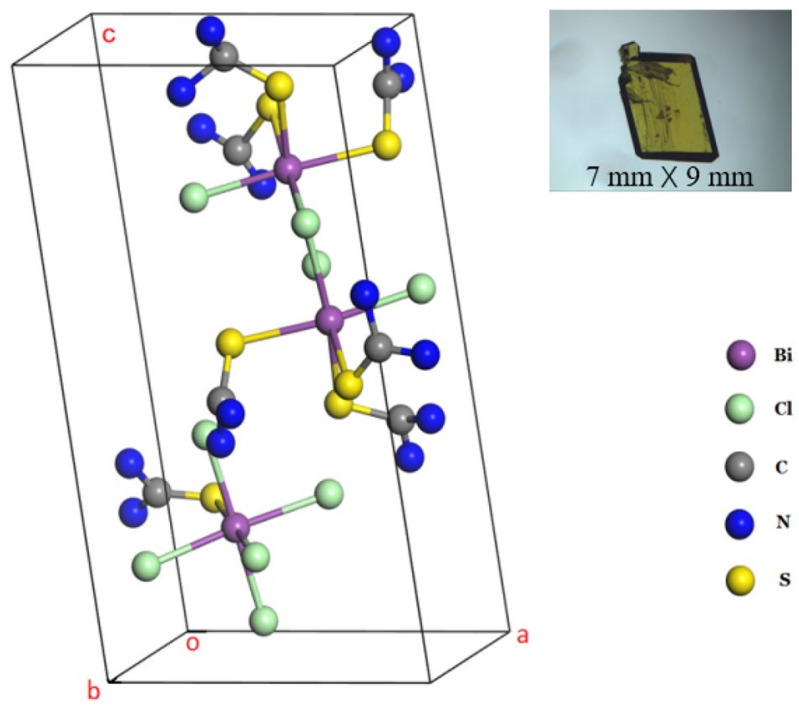

Fig. 1 Unit cell of the DCBPB crystal, $\mathrm{H}$ atoms are omitted; inset: microscopic photograph of DCBPB single crystal

Compared to other complexes formed by thiourea and bismuth chloride, a chlorine-bridge bond exists only in the $\left[\mathrm{Bi}_{2} \mathrm{Cl}_{4}\left(\mathrm{SC}\left(\mathrm{NH}_{2}\right)_{2}\right)_{6}\right]^{2+}$ cationic group of DCBPB crystal. Among those complexes with the same number of bismuth atoms, DCBPB crystals can form a distorted octahedron, which promotes the microcosmic NLO effect.

Such coordinating modes are different from those of $\alpha$ $\mathrm{BTC}$ [17] and $\beta$-BTC [18]. As a comparison, there is only one coordination mode in $\alpha$-BTC, in which each $\mathrm{Bi}^{3+}$ ion coordinates with three $\mathrm{Cl}^{-}$ions and three thiourea molecules. Moreover, in the $\beta$-BTC structure, one $\mathrm{Bi}^{3+}$ ion coordinates with six $\mathrm{Cl}^{-}$ions, one $\mathrm{Bi}^{3+}$ ion coordinates with six thiourea molecules, and the third $\mathrm{Bi}^{3+}$ ion coordinates with three $\mathrm{Cl}^{-}$ions and three thiourea molecules. For TBNTNC [19], the coordination modes are $(4+2),(2+4)$, and $(3+3)$.

\section{FTIR Analysis}

The FTIR spectra and characteristic peaks of thiourea and DCBPB are compared in Fig. 2 and Table 2. The peaks at 3174,3273 , and $3376 \mathrm{~cm}^{-1}$ are assigned to the $\mathrm{N}-\mathrm{H}$ stretching vibrations in thiourea molecule [21,22], which shift to higher frequencies in DCBPB. It demonstrates that nitrogenbismuth bonds are not present [23]. Apart from N-H deformation vibration (1614-1624 nm) and N-H stretching vibration (3193-3291 nm), other characteristic peaks all shift to lower frequencies. Compared to thiourea, the decreasing frequency of the peak corresponding to the $\mathrm{C}=\mathrm{S}$ stretching vibration in DCBPB indicates that $\mathrm{Bi}^{3+}$ ions coordinate with the sulfur atom of thiourea [21]. The main difference in FTIR spectrum between DCBPB and other known thiourea and bismuth chloride coordination compounds is that

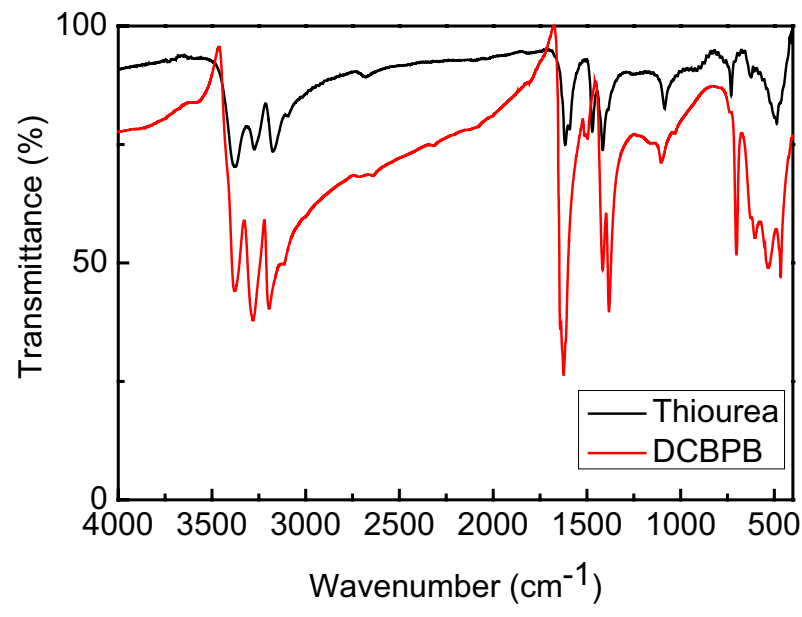

Fig. 2 FTIR spectra of DCBPB crystal and thiourea

the $\mathrm{N}-\mathrm{H}$ rocking vibrations shift to higher wavenumber in DCBPB, while do not substantially vary in the others, which may be due to a particular chlorine-bridge bond present in DCBPB.

\section{Optical Transmittance Spectrum Analysis}

Figure 3 shows the optical transmittance spectrum of DCBPB power crystal. The UV cut-off wavelength is $\sim 517 \mathrm{~nm}$, which is between the values of $\beta$-BTC $(560 \mathrm{~nm})$ and $\alpha$-BTC $(500 \mathrm{~nm})$. In the range of $500-2500 \mathrm{~nm}$, DCBPB crystal exhibits a relatively good transmittance, whereas, in the window of 500-1500 nm, DCBPB crystal shows excellent transmittance. In contrast, $\alpha$-BTC [17] has a distinguish absorption at $\sim 800-1300 \mathrm{~nm}$. The absorption peak around $1542 \mathrm{~nm}$ in the transmittance spectrum may be attributed to the second harmonic peak of the $\mathrm{N}-\mathrm{H}$ stretching vibrations. In the wavelength range from 500 to $1500 \mathrm{~nm}$, the transmittance of the grown powder crystal is $\sim 85 \%$ on average, which is about two times greater than that of $\alpha$-BTC [17] at the same wavelength range.

\section{Fluorescence Analysis}

The emission spectrum (Fig. 4) of DCBPB crystal shows a strong green photoluminescence emission at $508 \mathrm{~nm}$ $(2.45 \mathrm{eV})$, indicating that the DCBPB crystal has potential optical quality needed for the material to be NLO active [24].

\section{Thermal Analysis}

The thermostability of DCBPB crystal was investigated by TGA. Combining with the TG and differential thermal analysis (DTA) heat-flow curves (Fig. 5), the 
Table 2 FTIR band frequencies for thiourea, DCBPB, $\alpha$-BTC, $\beta$-BTC, and TBNTNC, and their corresponding vibrational modes

\begin{tabular}{lclccl}
\hline Thiourea & DCBPB & $\alpha$-BTC [17] & $\beta$-BTC [18] & TBNTNC [19] & Assignment \\
\hline 486 & 466 & 469 & 470 & 468 & $\delta(\mathrm{C}-\mathrm{N})$ \\
730 & 702 & 703 & 702 & 701 & $\nu(\mathrm{C}=\mathrm{S})$ \\
1085 & 1104 & 1100 & 1095 & 1097 & $\rho(\mathrm{N}-\mathrm{H})$ \\
1415 & 1382 & 1382 & 1384 & 1382 & $\nu(\mathrm{C}=\mathrm{S})$ \\
1470 & 1413 & - & 1428 & 1419 & $\nu(\mathrm{N}-\mathrm{C}-\mathrm{N})$ \\
1615 & 1624 & 1617 & 1619 & 1614 & $\delta(\mathrm{N}-\mathrm{H})$ \\
3174 & 3195 & 3192 & 3197 & 3197 & $\nu(\mathrm{N}-\mathrm{H})$ \\
3273 & 3281 & 3293 & 3193 & 3291 & \\
3376 & 3380 & 3880 & 3436 & 3387 & \\
\hline
\end{tabular}

$\delta$ deformation vibration, $\nu$ stretching vibration, $\rho$ rocking vibration



Fig. 3 Optical transmittance spectrum of DCBPB crystal

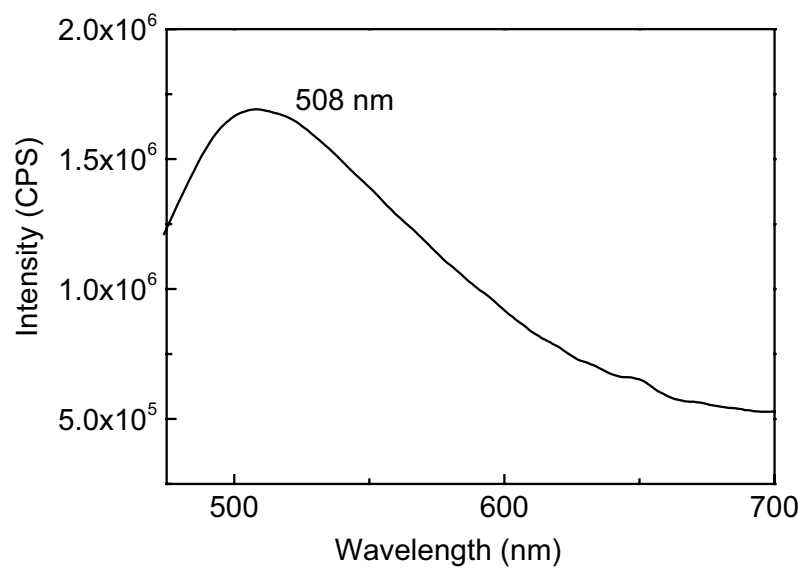

Fig. 4 Emission spectrum of DCBPB crystal

thermostability of DCBPB crystal can be divided into two stages. In stage 1 (from 25 to $189{ }^{\circ} \mathrm{C}$ ), only about $0.5 \%$ weight loss occurred and was attributed to the moisture. A solid-solid transition occurred, according to the

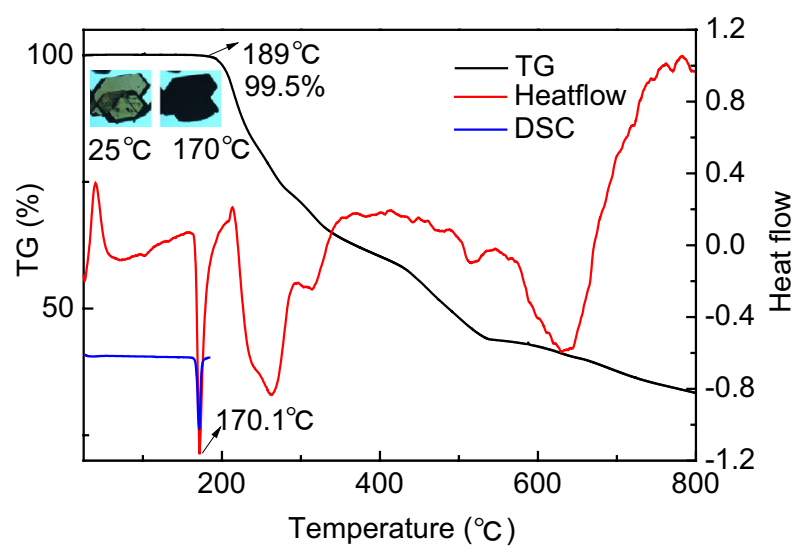

Fig. 5 TGA, DTA, and DSC curves of DCBPB crystals

endothermic peak at $170.1{ }^{\circ} \mathrm{C}$. The DSC curve of DCBPB confirms that the peak at $40{ }^{\circ} \mathrm{C}$ in DTA heat-flow curve could be attributed to the instrumental deviation.

The sample heated on HSM started to gradually turn into black from light yellow (Fig. 5) at $165{ }^{\circ} \mathrm{C}$. XRD patterns (Fig. 6) confirm the occurrence of the solid-phase transition at $170{ }^{\circ} \mathrm{C}$. FTIR spectrum analysis (Fig. 7) shows that, after the solid transition, peaks at 1384 and $703 \mathrm{~nm}(\mathrm{C}=\mathrm{S}$ stretching vibration) of DCBPB crystal remained unchanged, indicating that the coordination of $\mathrm{Bi}^{3+}$ ion with the sulfur atom was not damaged; however, the $\mathrm{N}-\mathrm{H}$ stretching vibration peaks of DCBPB crystal are distinctly different, implying that the solid transition reaction may have generated ammonium ions. Stage 2 (from 189 to $296{ }^{\circ} \mathrm{C}$ ) corresponds to the decomposition of DCBPB crystals in two steps. In step 1, there was a $28 \%$ reduction in weight, which is mainly due to the release of some inorganic nonmetal gas produced by the decomposition of DCBPB crystals, such as $\mathrm{CS}_{2}, \mathrm{COS}$, or $\mathrm{NH}_{2} \mathrm{CN}$ $[25,26]$. In step 2 , the further weight loss at $536{ }^{\circ} \mathrm{C}$ is attributed to the volatilization and oxidation of remaining products including the carbon oxides, sulfide, or bismuth chloride [17]. 


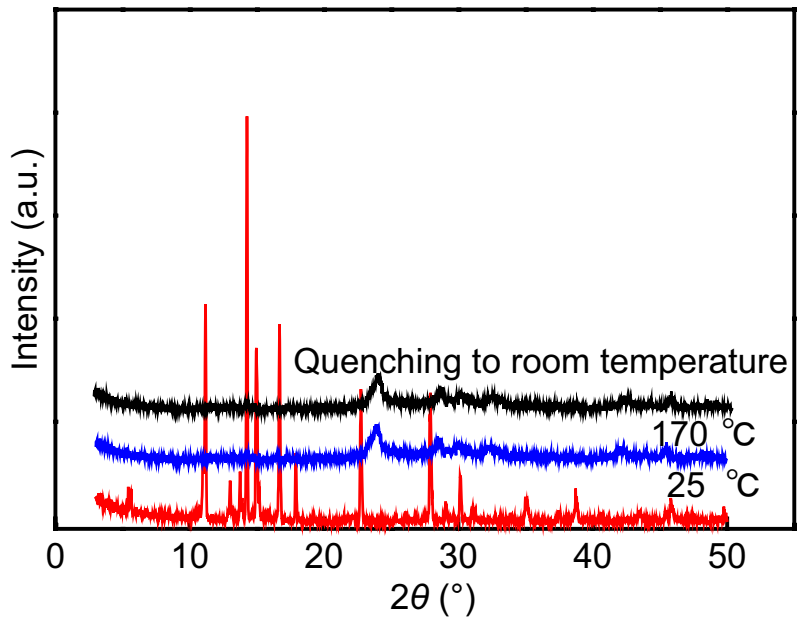

Fig. 6 XRD patterns of DCBPB at $25,170{ }^{\circ} \mathrm{C}$, and after quenching to room temperature

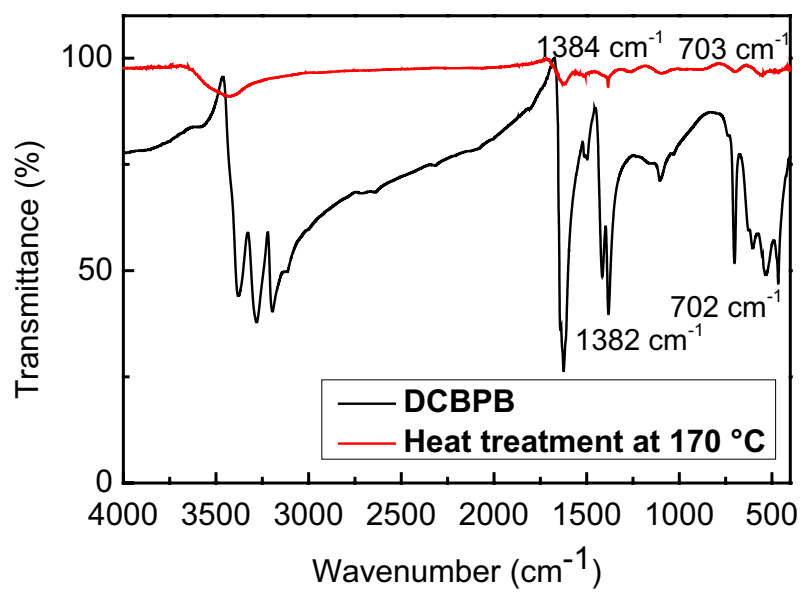

Fig. 7 FTIR spectra of DCBPB crystal and after the heat treatment at $170{ }^{\circ} \mathrm{C}$

\section{SHG Test}

The result of the SHG test showed that the effective SHG coefficient of DCBPB crystal was estimated to be about twoseventh of $\mathrm{KH}_{2} \mathrm{PO}_{4}(\mathrm{KDP})$ crystal, which is slightly higher than the value of $\alpha$-BTC [17] but smaller than that of $\beta$-BTC [18].

\section{Conclusion}

A new single semi-organic crystal of DCBPB was grown from bismuth chloride and thiourea in formic aqueous solution via the slow evaporation method. DCBPB crystallizes in the triclinic system. The light transmittance of the crystal is two times higher than the value of $\alpha$-BTC at a wavelength range of 500-1500 $\mathrm{nm}$. The crystal shows green fluorescent emission at $508 \mathrm{~nm}$. The second-order NLO efficiency is two-seventh of the standard KDP. DCBPB is thermally stable at temperatures below $165^{\circ} \mathrm{C}$. It undergoes a solid-solid reaction at $170{ }^{\circ} \mathrm{C}$ and decomposes at temperatures above $189{ }^{\circ} \mathrm{C}$. Therefore, the synthesized DCBPB exhibits structural and optical properties that render it a promising candidate for frequency conversion applications.

Acknowledgements The authors acknowledge the support by the National Key Research and Development Program of China (No. 2016YFC0400408).

Open Access This article is distributed under the terms of the Creative Commons Attribution 4.0 International License (http://creativeco mmons.org/licenses/by/4.0/), which permits unrestricted use, distribution, and reproduction in any medium, provided you give appropriate credit to the original author(s) and the source, provide a link to the Creative Commons license, and indicate if changes were made.

\section{References}

1. Franken PA, Hill AE, Peters CW et al (1961) Generation of optical harmonics. Phys Rev Lett 7(4):118-119

2. Dmitriev VG, Gurzadyan GG, Nikogosyan DN (1999) Handbook of nonlinear optical crystals. Springer, New York

3. Jang SH, Jen AK (2009) Electro-optic (E-O) molecular glasses. Chem Asian J 4(1):20-31

4. Wu K, Chen X, Snijders JG et al (2002) Theoretical studies of nonlinear optical crystals in metal cluster compounds. J Cryst Growth 237-239(1):663-667

5. Jiang MH, Fang Q (1999) Organic and semiorganic nonlinear optical materials. Adv Mater 11(13):1147-1151

6. Liu XT, Wang XQ, Lin XJ et al (2012) Growth, characterization and theoretical study of a novel organometallic nonlinear optical crystal: $\mathrm{CdHg}(\mathrm{SCN})_{4}\left(\mathrm{C}_{2} \mathrm{H}_{5} \mathrm{NO}\right)_{2}$. Appl Phys A 107(4):949-957

7. Bouchouit K, Essaidi Z, Abed S et al (2008) Experimental and theoretical studies of NLO properties of organic-inorganic materials base on $p$-nitroaniline. Chem Phys Lett 455(4-6):270-274

8. Lal RB, Frazier DO (2002) Crystal materials for nonlinear optical devices and microgravity science. In: Proceedings of SPIE-the international society for optical engineering, vol 4813

9. Bouchouit K, Bendeif EE, Ouazzani HE et al (2010) Correlation between structural studies and third order NLO properties of selected new quinolinium semi-organic compounds. Chem Phys 375(1):1-7

10. Kirupavathy SS, Mary SS, Srinivasan P et al (2007) Investigations on the growth and characterization studies of cadmium thiourea acetate (CTA) single crystals. J Cryst Growth 306(1):102-110

11. Bierbach U, Hambley TW, Farrell N (1998) Modification of platinum (II) antitumor complexes with sulfur ligands. 1. Synthesis, structure, and spectroscopic properties of cationic complexes of the types $[\mathrm{PtCl}($ diamine $)(\mathrm{L})] \mathrm{NO}_{3}$ and $\left[\{\mathrm{PtCl}(\text { diamine })\}_{2}(\mathrm{~L}-\mathrm{L})\right]$ $\left(\mathrm{NO}_{3}\right)_{2}(\mathrm{~L}=$ monofunctional thiourea derivative; $\mathrm{L}-\mathrm{L}=$ bifunctional thiourea derivative). Inorg Chem 37:708-716

12. Antochshuk V, Olkhovyk O, Jaroniec M et al (2003) Benzoylthiourea-modified mesoporous silica for mercury(II) removal. Langmuir 19(7):3031-3034

13. Di Bella S, Fragalà I, Ledoux I et al (1997) Synthesis, characterization, optical spectroscopic, electronic structure, and second-order nonlinear optical (NLO) properties of a novel class of 
donor-acceptor bis(salicylaldiminato)nickel(II) Schiff base NLO chromophores. J Am Chem Soc 119(40):9550-9557

14. Xing G, Jiang M, Shao Z et al (1987) Bis-thiourea cadmium chloride (BTCC)-A novel nonlinear optical crystal of organometallic complex. Chin J Lasers 5:48-54

15. Rajasekaran R, Ushasree PM, Jayavel R et al (2001) Growth and characterization of zinc thiourea chloride (ZTC): a semiorganic nonlinear optical crystal. J Cryst Growth 229(1-4):563-567

16. Ushasree PM, Jayavel R, Subramanian C et al (1999) Growth of zinc thiourea sulfate (ZTS) single crystals: a potential semiorganic NLO material. J Cryst Growth 197(1-2):216-220

17. Li M, Li RK (2013) Crystal growth and characterization of a new polymorph of bismuth trithiourea chloride. CrystEngComm 15(20):4176-4180

18. Bhat SG, Dharmaprakash SM (1998) A new metal-organic crystal: bismuth thiourea chloride. Mater Res Bull 33(6):833-840

19. Krishnakumar V, Saleem SS, Prasad LG (2009) Crystal structure, vibrational, and optical investigations of semiorganic nonlinear optical crystal: Bi3[CS(NH2)2]9C19 2H2O. J Raman Spectrosc 40(8):1011-1015

20. Kurtz SK, Perry TT (1968) A powder technique for the evaluation of nonlinear optical materials. J Appl Phys 39:3798-3813
21. Yamaguchi A, Penland RB, Mizushima S et al (1958) Infrared absorption spectra of inorganic coördination complexes. XIV. Infrared studies of some metal thiourea complexes ${ }^{1 \mathrm{a}}$. J Am Chem Soc 80(3):527-529

22. AlíA JM, Edwards HGM, Stoev MD (1999) A systematic FTRaman spectroscopic study of twelve bis-thiourea complexes, $\mathrm{A}(\mathrm{tu}) 2 \mathrm{~B} 2(\mathrm{~A}=\mathrm{Zn}, \mathrm{Cd}, \mathrm{Hg} ; \mathrm{B}=\mathrm{Cl}, \mathrm{Br}, \mathrm{I}, \mathrm{SCN})$. Spectrochim Acta Part A Mol Biomol Spectrosc 55(12):2423-2435

23. Brunetti B, Gozzi D, Iervolino M et al (2006) Bismuth activity in lead-free solder Bi-In-Sn alloys. CALPHAD Comput Coupling Phase Diagrams Thermochem 30(4):431-442

24. Anis M, Shaikh RN, Shirsat MD et al (2014) Investigation of optical and electrical properties of L-Cystein doped zinc thiourea chloride (ZTC) crystal for nonlinear optical (NLO) applications. Opt Laser Technol 60:124-129

25. Madarász J, Bombicz P, Okuya M et al (2004) Online coupled TG-FTIR and TG/DTA-MS analyses of the evolved gases from dichloro(thiourea) tin(II). Solid State Ionics 172(1-4):577-581

26. Madarász J, Krunks M, Niinistö L et al (2004) Evolved gas analysis of dichlorobis(thiourea) zinc(II) by coupled TG-FTIR and TG/ DTA-MS techniques. J Therm Anal Calorim 78(2):679-686 